\title{
The Development Trend of University Library Changing from Resource Center to Knowledge Service Center
}

\author{
Chunyue Liu \\ Library, Jilin Business and Technology College, Changchun ,China \\ 1136146431@qq.com
}

Keywords: Universities' libraries; Resource Center; Service Centre; Change

\begin{abstract}
The university library is the document information center and the most important teaching unit in the school. It has a lot of digital resources and paper resources to provide the readers with the literature resources service, but is the library development only the purchase of a certain scale of resources? Is reader's expectation of library resource only? Although the literature resources are the core elements of the library, but with the development of intelligent technology, what is the future library to do and what is the future direction of the library development? From this point of view, this paper discusses the trend of library development from the resource center to the service center.
\end{abstract}

\section{Analysis of Environmental Changes}

One aspect of the development of the library is the environment, which is in fact beyond our imagination. The British Library's strategic planning (2008-2011 years) says:" the changes in our environment over the past twenty years have exceeded the changes of the past two hundred years, especially the drive for technological development. This change is gradually changing the traditional academic research on the dependence of the physical library as an important source of information to meet the needs of the research, and to a complex network with a variety of options (different levels of access, authority, depth). [1] Nowadays, people mostly get information from the Internet and support his research, rather than to our physical library. This is a very big change. Scott Nicholson, a university professor in the United States, said that "the changes in the library world over the past five years have exceeded the changes in the previous one hundred years, and the changes in the next five years will make the changes of the past five years become insignificant". [2] in such a changing environment, libraries should be changed accordingly. This is mainly from the following aspects of the movement:

The Change of Information Environment. Now we feel that more environment is network environment, infinite environment, even intelligent environment. User needs have changed and user behavior has changed. We know more and more that more and more readers are not in the library, the library is generally undergraduate, but do graduate students really do not need physical libraries? Some researchers use library databases, but he doesn't care who they buy. In turn, the library can only buy resources. Is it the library's ability? The school gives you money to buy resources, and anyone will buy it. Is this the level of the library? The reader, especially the scientific research type, does not get to the library, this is a trend. It must be a choice of his behavior. So the library must make embedded services. If he doesn't come, we will go to his side. When undergraduate students go to the library, he is also using the place and space of library. But how many people are using our resources and how many people are using our services? Although the number of undergraduates to libraries is large, are we merely serving undergraduates? So we are an undergraduate library, those who do not go to library teachers, researchers, principals how do we serve? If we don't serve, we will lose a large part of the readers. Therefore, It is easy to serve undergraduate student of the library we have places, resources, and space, but for those who do not get to the library how to do service is the biggest challenge to the library.

Changes of Publishing. Allen, Elsevier head of technology services research and development laboratory, At present, academic publishing has gone beyond the stage of paper publishing, and has 
developed from the development stage of digital library to the stage of service platform. In the paper publication stage, the academic achievements are published in the form of monograph or periodical paper, paper dissemination, retrieval and acquisition through library. The digital library phase is to publish the academic achievements in the form of monograph or periodical paper, digital form, search engine and obtain by search engine. In the service platform phase (It is expected to start from 2010), academic achievement was released based on program and application programming interface, transmitted in digital form, and discovered and acquired through social networking. A qualitative leap in the mode of academic exchange[3], Now the circulation of paper is decreasing at a rate of $80 \%$. Theoretically, there will be no paper publication in ten years, and the future development will go to digitalization rapidly.

Changes of Expectations of Society. Social desirability needs different libraries from traditional libraries. The library can solve what kinds of needs the users meet and what new needs they meet. Now, the cognition of research users is the Internet can't find no, It is equal to no existence. This sentence reflects the basic cognition and behavior of many researchers. He won't choose to go to the library to find the literature. Foreign scholars have said, "when all information is available online, do we need libraries?" This is also a problem that the library counterparts need to consider. Of course, not all information can be obtained online. Some databases can't find on the Internet, Not open access .A situation like this requires us to rethink. This is a concern of the mass media, and it is also a concern of the society. Industry career that will disappear in the future include librarians. Because librarians can only do some work without thinking. The work of things may be replaced by machines in the future. Be replaced by artificial intelligence. Nanjing University development library treasure robot.But your professional work will not be replaced. Scientific research is more integrated into your knowledge, your intelligence and your ability. Intelligent technology can't affect human intelligence and human emotion. Therefore, librarians need more wisdom and emotion. If we say that service is emotional, it will not be replaced. So we have to redefine the library It is not an entity library to call a library. It is not marked by the building of a physical library. The library is more of a function. We can provide our resources and services through user's network, virtual community and so on, all of which are functions of library. If we do what users expect and users need, then the library will not be marginalized.

\section{The Value of the Library is Mainly Embodied in Three Aspects}

Providing the Use of Knowledge. You can help users feel that it is helpful for you to organize and analyze documents, especially after digging. But the traditional library provides the use of the literature. has been very common abroad. Our subject librarians can really embed very few. The library is about links, this link is the association between people, the association between institutions and institutions, and the correlation between data and data, so the library is of value. There are many research platforms, and he integrates all the people, all things, and all the activities in this field on one platform, in fact it is related. This is the value of your library. Rush G. Miller "Library is not about books, neither is it about information, it's about the connection between people" [4], The library is the collection of your resources, you, your house, your space, do the association between services and people you, Another report mentioned" the size of the collection will quickly lose his importance"

Evaluation of Library Standards. The previous indicators are input and scale, In fact, all the collections, the total funds of periodicals, the number of readers coming to the library, the number of reference services and the number of training people are actually invested. And now it is the evaluation of the output and the effectiveness of the library, that is, from input to output. Just like an enterprise, I have invested so much raw materials and funds. What is the quantity and quality of my output? What is the performance of my market? In the past, we paid more attention to the former and paid less attention to the latter. The output and effectiveness of university library is the impact of enrollment rate, retention rate and graduation rate. Influence on students' learning. Does he make use of your library to help him, the contribution to the teacher's scientific research productivity, the 
teacher do scientific research can make use of your resources and service to do his scientific research better and faster, the influence on the teacher support, the support to the teacher's teaching, these are all output. We talk about embedded teaching, the principal will see your output, you will see the contribution to the school, so how to plan and design our service is very important.

Traditional User Needs and New Needs. The problem of demand is very important. If libraries often don't know what to do or do not do well, they often don't know about users' needs, and don't know what users need. Users do not know what libraries can do, and the existence and development of libraries must depend on their needs. If a university library makes an investigation of the undergraduates, the undergraduates will be very satisfied with the library. The results will be disappointed if the teachers, the researchers and the chief executive are investigated. Even if he uses the library's website, he doesn't think much of the library's contribution. If these users don't need the library, it will be a big problem. So the demand is very important. Readers who come to the library are easier to serve. What are their needs for users who don't come to libraries? Library's understanding and cognition to users is not enough, so the demand determines the existence of libraries. The traditional service of the library is the literature service. The traditional ability of librarians is the ability of the literature. Now users' needs are moving from resources to services. Demand determines service. This is a fundamental change. The problem of resources can always be solved. No resources can be purchased, shared or coordinated. Service is the most concern of users today. The quality of service actually depends on the degree of user satisfaction. Traditional service is to satisfy users' general needs. Today's era is to meet users' potential needs. He needs a book. What's behind it? Maybe he needs to do a project. , and the topic is not just this book. So we dig out his potential needs, and the responsibility of the library is to know and dig out the needs of the users. Only by the teachers and researchers can they know their needs. so we have to integrate into the user's virtual community to understand his needs. Through some of his information, data mining, personalized tracking, these are all we can do, today this era must be a service era.

The New Service Ability of the Library. The resources of the library are limited, and the service is unlimited. Because the funds are limited, your service will do a lot of things. So the difference between libraries is the difference of service, rather than the difference of resources. A library is good and bad, it must be your service good and bad, so the user and service is the core of all activities in the library. The ability of the library must be based on the level and effect of your service, and the ability of the resources must be transformed into the ability of service.

The way to know the needs: The new way is the regular integration into mechanism of subject librarians. It is a very important responsibility of a subject librarian to understand and dig out the needs of the user anytime and anywhere, because you are often with the user, so you know what he needs. Integrating into the user's virtual community, his blog, his micro-blog, his friends circle, he may publish his needs in this place. Some of his information can also be used to mine data of users' logs by means of technology. And then do personalized tracking. We can all do this. The new service ability of the library, the needs of the user to knowledge rather than the demand for the literature, has surpassed the literature level, but is the content of knowledge. The service of the library is a knowledge service embedded in the process of the user. It is not enough to provide only literature service. It must be his knowledge, his management process, The complete concept of subject librarians is embedded knowledge service. Knowledge service needs your knowledge and your intelligence. Librarians' ability is based on the research service ability of research. If you can't think with scientific thinking, you can't do well. What you do is a very simple service, so doing service is based on research. Service based research capability is built on the basis of service.

\section{Conclusion}

In short, we are not doing theoretical research, nor doing other disciplines. The library is for service, which is the professional orientation of librarians. We do academic services and knowledge consultation, provide solutions instead of an article. Reflecting the creativity and increment of knowledge, it must be knowledge and research. Now the library is the digital library, the mobile library, the intelligent library age. The relationship between us and the scientific researchers is the 
relationship of the partners, and it is better to communicate with the users by scientific thinking and methods. It must be high education and high quality. Without this level, you can't do it. The development trend of the library in the future must change from the center of the resources to the service center, which is the only way for the library to survive and develop.

\section{References}

[1] J.L.CHU, D.M. WU Research Report on the development trend of Library (1): Environmental analysis and major strategies [J] Journal of the National Library of China. 2(2010):3-10.

[2] J.L.CHU, D.M. WU Research Report on the development trend of Library(3): Resource construction and user service [J] Journal of the National Library of China 2010 ( 07 ) : 3-8

[3] J.H. Wu , Y.C. Chen \& Li-Min Lin. Empirical evaluation of the revised end user computing acceptance mode[J]Computers in Human Behaviors 2007, 23(1):162-174.

[4] Zajonc, R. B.\& Markus, H. Affective and cognitive factors in preferences[J]. Journal of Consumer Research, 1982(9): 123-131.

[5] X.L. Zhang The big trend of the digital library. [J] Journal of Chinese Library 2015 ( 5 ) :4-11.

[6] Zhang, Y \& Estabrook, L. Accessibility to Internet-based electronic resources and its implications for electronic scholarship [C]. Proceedings of the American Society for Information Science Annual Meeting, 1998(35): 463-473. 